\title{
Antibiogram and Phenotypic Characterization of $E$. Coli Isolated from Nigeria's Paper Currencies obtained from Butchers in Ebonyi State
}

\author{
Moses IB ${ }^{1 *}$, Ugbo EN ${ }^{1}$, Odah EE ${ }^{1}$, Iroha IR ${ }^{1}$, Agumah NB ${ }^{1}$, Ukpai EG ${ }^{2}$, Eluu SC ${ }^{2}$, Uzoeto HO ${ }^{1}$, Okamkpa \\ $\mathrm{CT}^{3}$ and Okata-Nwali $\mathrm{D}^{4}$
}

${ }^{1}$ Department of Applied Microbiology, Faculty of Sciences, Ebonyi State University, P.M.B. 053, Abakaliki, Ebonyi State, Nigeria

${ }^{2}$ Department of Biotechnology, Faculty of Science, Ebonyi State University, P. M. B. 053 Abakaliki, Ebonyi State, Nigeria

${ }^{3}$ Department of Medical Laboratory science, University of Nigeria, Nsukka, Nigeria

${ }^{4}$ Department of Biology/Microbiology/Biotechnology, Alex Ekweme Federal University Ndufu-Alike, Ikwo Ebonyi State, Nigeria

${ }^{*}$ Corresponding author: Moses IB, Department of Applied Microbiology, Faculty of Sciences, Ebonyi State University, P.M.B. 053, Abakaliki, Ebonyi State, Nigeria, Tel: +2348134136233; E-mail: ben_iyke70@yahoo.com

Received date: June 27, 2018; Accepted date: August 22, 2018; Published date: August 29, 2018

Citation: Moses IB, Ugbo EN, Iroha IR, Ukpai EG, Odah EE, et al. (2018) Antibiogram and Phenotypic Characterization of E. Coli Isolated from Nigeria's Paper Currencies obtained from Butchers in Ebonyi State. Arch Clin Microbiol Vol No:9 Iss No:4:85

Copyright: (c) 2018 Moses IB, et al. This is an open-access article distributed under the terms of the Creative Commons Attribution License, which permits unrestricted use, distribution, and reproduction in any medium, provided the original author and source are credited.

\section{Abstract}

This study was designed to phenotypically characterize and determine the antibiotic resistance patterns of $E$. coli isolated from Nigeria's paper currencies obtained from butchers in Abakaliki meat market, Ebonyi State. A total of 98 samples of naira notes in different denominations (N5 to N1000) were randomly collected from butchers and were analyzed using standard microbiological procedures. The isolated bacterial pathogens were subjected to antibiotic susceptibility test on Mueller-Hinton agar (Oxoid, England) by Kirby Bauer disc diffusion technique. A total of 7 (7.1\%) Escherichia coli isolates were obtained in which two exhibited multi-drug resistance trait. The Escherichia coli isolates were highly resistant to ceftazidime (85.7\%). The highest susceptibility frequency was observed for ciprofloxacin $(100 \%)$, imipenem $(100 \%)$, meropenem $(100 \%)$ and ofloxacin $(100 \%)$. There was a statistically significant difference in the mean percentage resistance and mean percentage susceptibility $(\mathrm{P}<0.05)$ of the $E$. coli isolates. The multiple antibiotic resistance indices (MARI) of the Escherichia coli isolates ranged from 0.14-0.43. These high MARI values might be an indication of abuse and misuse of antibiotics. Escherichia coli can cause serious communityacquired infections. Hence, appropriate hygienic measures should be adopted while handling naira notes.

\section{Keywords: Antibiotic resistance; Butchers; Paper} currencies; Escherichia coli; Multi-drug resistance

\section{Introduction}

Currency is handled by all categories of people and may be contaminated during coughing, sneezing, touching with hands and placement on dirty surfaces. Many people tongue-wet their finger when counting money thereby contaminating their fingers as well as currency notes. So, it is obvious that anything that gets on hands may be transferred to money vice versa. Search for contaminated currency which started in early 1970S, reported potential pathogens of $13 \%$ on coins and $42 \%$ on paper currency. Contaminated banknote (paper currency) is any currency that has been exposed to some biological and chemical contaminants. Banknotes serve as an ideal breeding ground for microorganisms. Contaminated banknotes or coins could be a public health risk as it is handled by everyone $[1,2]$. Contamination may occur from the general public in community, hospitals and food outlets or during use, storage or production. During handling, contamination from the skin, anal region, wounds, nasal secretions and aerosols are main sources of transferring microorganisms to banknotes during handling [1]. Therefore, banknotes have an important role in the transmission of pathogenic microorganisms and present a risk to public health. The biological contamination could be virus, fungal spores, or bacteria. The microorganisms known to be transferred by circulating banknotes in community are Escherichia coli, $S$. epidermidis, Streptococcus, Pseudomonas aeruginosa, and Klebsiella aerogenes [3]. The main microorganisms that are known to be transferred by circulating banknote recovered from hospitals are E. coli, S. aureus, Salmonella spp. [4,5] and that recovered from food outlets is $S$. aureus, and sometimes $E$. coli. It is noted that there is an increasing multi-drug resistant (MDR) bacterial strains where the bacteria demonstrate resistance to more than one class of antibiotics [6]. Few studies had focused on antibiotic resistance among bacteria recovered from banknotes [7]. Contaminated banknotes and coins contribute to the transmission of multi-drug resistant microorganisms in the community such as MRSA and vancomycin-resistant enterococci (VRE) $[8,9]$. It is also noted that antimicrobial resistance such extended-spectrum beta lactamases (ESBL)-producing $E$. coli and Klebsiella spp. has steadily been increasing [10]. Today, disinfectants used for human hygiene purposes make an essential component of human health care approach as they aim 
to remove and destroy harmful and undesirable microorganisms. This study is therefore designed to determine the antibiotic resistance patterns of $E$. coli isolated from Nigeria's paper currencies obtained from butchers in Abakaliki meat market, Ebonyi State.

\section{Materials and Methods}

Study area: Ebonyi State is popularly known as the 'Salt of the Nation,' apparently because of the large deposits of salt water in the state. The State capital is Abakaliki. It lies approximately within longitude $7030^{\prime}$ and $8030^{\prime} \mathrm{E}$ and $5040^{\prime}$ and $6045^{\prime} \mathrm{N}$. According to data from the 2006 Population and Housing Census, Ebonyi State has an estimated population of 2.3 million and a land mass of $5,935 \mathrm{~km} 2$.

\section{Collection of samples}

A total of 98 samples of naira notes in different denominations (N5 - N1000) were randomly collected from butchers at meat market, within Abakaliki metropolis between the months of April and June, 2016. The naira notes were collected with hands covered with sterile gloves. The notes were then immediately placed inside sterile polythene bags and labeled accordingly. In some instances, the naira notes were obtained during exchange for bigger denominations; others were obtained after buying items with bigger denominations. The naira note samples were then immediately transported to the department of Applied Microbiology laboratory, Ebonyi State University, Abakaliki, Nigeria for bacteriological analysis. The currencies were observed to have been in circulation for about 2-4 years (2011-2014). Mint paper currencies were used as controls.

\section{Culturing, isolation, phenotypic characterization and identification of the isolates}

A sterile swab stick moistened with sterile physiological saline $(0.85 \% \mathrm{NaCl})$ was used to swab both sides of each note. Each of the swabs was then aseptically transferred into test tubes containing $5 \mathrm{ml}$ of peptone water and incubated overnight at $37^{\circ} \mathrm{C}$. After incubation, the swabs were then streaked onto already prepared Eosin Methylene Blue (EMB) agar (Oxoid, UK). The inoculated plates were then incubated at $37^{\circ} \mathrm{C}$ for 24 hours. Colonies displaying typical Escherichia coli characteristics (green metallic sheen) were picked and sub-cultured on freshly prepared EMB agar plates so as to obtain pure colonies. Pure colonies (one pure colony per culture plate was selected) of $E$. coli isolates were picked from the EMB agar plates and inoculated on prepared nutrient agar slants and preserved in the refrigerator at $4^{\circ} \mathrm{C}$ for further tests. The suspected $E$. coli isolates were further characterized using conventional/standard microbiology techniques such as colony morphology, Gramstaining, catalase test, motility test, and other biochemical tests which include oxidase test, indole test, citrate utilization test, $\mathrm{H} 2 \mathrm{~S}$ production test, Voges-Proskauer test, methyl red test, urease test, nitrate reduction test, and sugar fermentation test [11].

\section{Antibiotic susceptibility test}

Antibiotic susceptibility of the $E$. coli isolates was done using the Kirby Bauer disc diffusion method and interpreted according to the guidelines of Clinical Laboratory Standards Institute (CLSI, 2007) formerly known as National Committee for Clinical Laboratory Standards (NCCLS). Mueller-Hinton agar was prepared according to the manufacturer's instructions. The medium was cooled to $45-50^{\circ} \mathrm{C}$ and poured into plates. Plates were allowed to set on a level surface to a depth of approximately $4 \mathrm{~mm}$. When the agar has solidified, plates were allowed to dry before use. An 18-24 hour old broth culture of the $E$. coli isolate was standardized by diluting to 0.5 Mcfarland's standard. A sterile swab stick was inserted into the standardized $E$. coli inoculum, drained to remove excess inoculum load and inoculated by spreading on the surface of prepared MuellerHinton agar plate. After this, the inoculated Mueller-Hinton agar plate was allowed to dry for a few minutes at room temperature with the lid closed. After the agar surface has dried for few minutes, antibiotic impregnated discs (Oxoid, UK) of known concentrations; gentamycin $(30 \mu \mathrm{g})$, aztreonam (30 $\mu \mathrm{g})$, ofloxacin $(5 \mu \mathrm{g})$, ceftazidime $(30 \mu \mathrm{g})$, cefepime $(30 \mu \mathrm{g})$, meropenem $(10 \mu \mathrm{g})$, ciprofloxacin $(5 \mu \mathrm{g})$, and imipenem $(10 \mu \mathrm{g})$ were carefully applied on the inoculated Mueller-Hinton agar plates using sterile forceps. The plates were then incubated at $37^{\circ} \mathrm{C}$ for $18-24$ hours. After incubation, the diameters of the zones of inhibition were measured with a ruler to the nearest millimeter and recorded. The results were recorded as resistant, intermediate and susceptible according to the guidelines of Clinical Laboratory Standards Institute [12].

\section{Determination of multiple antibiotics resistance index (MARI)}

Multiple antibiotic resistance indices (MARI) of the E. coli isolates were calculated using the technique described by Christopher et al. [13] and Subramani et al. [14]. This was calculated as the number of antibiotics to which the tested isolate was resistant to (a), divided by the total number of antibiotics that was tested on the isolates (b).

\section{Statistical Analysis}

Categorical variables of the mean resistances of the isolates were compared their mean susceptibilities using T-test and Pearson correlation index at $\mathrm{P}<0.05$ with statistical software, SPSS Data Editor Version 16.

\section{Results}

The Escherichia coli isolates were resistant to ceftazidime $(85.7 \%)$. This was closely followed by aztreonam $(42.9 \%)$ and cefepime (28.6\%). The highest susceptibility frequency was observed for ciprofloxacin (100\%), imipenem (100\%), meropenem (100\%) and ofloxacin (100\%). This was closely followed by gentamicin ( $85.7 \%$ ). The results of the one sample ttest conducted showed that there was no statistically significant difference in the mean percentage resistance of the $E$. coli isolates (mean=21.4375, $\mathrm{SD}=30.54462$ ), $\mathrm{t}=1.985, \mathrm{P}=0.088$ (at 
$\mathrm{P}<0.05)$. One sample t-test showed that there was a statistically significant difference in the mean percentage susceptibilities of the $E$. coli isolates (mean=78.5625, $S D=30.54462$ ), $t=7.275$, $\mathrm{P}=0.000 \quad(\mathrm{P}<0.05)$. Results of the independent samples $t$-test conducted to compare the percentage resistances and percentage susceptibilities of the $\mathrm{E}$. coli isolates to different classes of antibiotics showed that there was a statistically significant difference in the mean percentage resistance (mean=21.4375, SD=30.54462) and mean percentage susceptibility (mean=78.5625, $\mathrm{SD}=30.54462) ; \mathrm{t}=-3.740, \mathrm{P}=0.002$ $(P<0.05)$.

\section{Discussion}

Paper currencies have been accepted and used as a means of exchange and legal tender for centuries. However, these currencies are often times predisposed to microbial contamination due to the way they are handled. Bacteria, such as Escherichia coli, have frequently been implicated in the contamination of paper currencies used for transactions. This study was designed to determine the antibiotic resistance patterns of $E$. coli isolated from Nigeria's paper currency obtained from butchers in Abakaliki meat market, Ebonyi State.

Table 1 Currency type positive for E. coli.

\begin{tabular}{|l|l|l|l|l|}
\hline S/N & $\begin{array}{l}\text { Currency } \\
\text { Type(N) }\end{array}$ & $\begin{array}{l}\text { Smooth } \\
\text { and Neat }\end{array}$ & $\begin{array}{l}\text { Rough } \\
\text { and Dirty }\end{array}$ & $\begin{array}{l}\text { E. coli } \\
\text { growth } \\
\text { after 24 } \\
\text { hours }\end{array}$ \\
\hline 1. & 10 & - & + & + \\
\hline 2. & 50 & - & + & + \\
\hline 3. & 100 & - & + & + \\
\hline 4. & 1000 & - & + & + \\
\hline 5. & 200 & - & + & + \\
\hline 6. & 20 & - & + & + \\
\hline 7. & 500 & - & + & + \\
\hline 8. & Control (mint) & + & - & - \\
\hline
\end{tabular}

Key: + indicates Positive; - indicates Negative

All the naira notes (rough and dirty) were positive for E. coli except the control (mint).

A total of 98 naira notes ranging from N 5 to N1000 obtained from butchers at Abakaliki meat market were used for this study while a Naira note in mint condition was used as a control. All the 98 naira notes obtained from butchers at meat market, Abakaliki showed bacterial growth after 24 hours. All the naira notes that had bacterial growths were rough and dirty in appearance. The control (mint) obtained from a commercial bank in the same study area did not show any bacterial growth. Out of the 95 naira notes obtained for this study, 7 were positive for $E$. coli growth after 24 hours of incubation at $37^{\circ} \mathrm{C}$ (Table 1 ).
This report is in agreement with the work of Ayandele and Adeniyi [15] who also isolated Escherichia coli from Naira notes obtained from traders in Ogbomosho, South-Western Nigeria. We recorded $7.14 \%$ E. coli frequency in our study. This E. coli frequency of $7.14 \%$ in our study is similar to a report from Pakistan by Abiodoun et al. (2011), who recorded $13 \%$ E. coli frequency among isolates recovered from paper currencies. The Escherichia coli isolates were resistant $(85.7 \%)$ to ceftazidime. This was closely followed by aztreonam (42.9\%) (Table 2 ).

Table 2 Percentage occurrence of responses of the Escherichia coli isolates to different antibiotics.

\begin{tabular}{|l|l|l|}
\hline Antibiotics Used & Resistance (\%) & Susceptible (\%) \\
\hline Ciprofloxacin & $0(0.00)$ & $7(100)$ \\
\hline Cefepime & $2(28.6)$ & $5(71.4)$ \\
\hline Gentamicin & $1(14.3)$ & $6(85.7)$ \\
\hline Aztreonem & $3(42.9)$ & $4(57.1)$ \\
\hline Meropenem & $0(0.00)$ & $7(100)$ \\
\hline Imipenem & $0(0.00)$ & $7(100)$ \\
\hline Ofloxacin & $0(0.00)$ & $7(100)$ \\
\hline Ceftazidime & $6(85.7)$ & $1(14.3)$ \\
\hline
\end{tabular}

This observation is similar to the study carried out by Anyadele and Adeniyi [15] in Ogbomosho, South-Western Nigeria where they reported that Escherichia coli recovered from paper currencies were resistant to ceftriaxone, gentamicin, trimethoprim-sulfamethoxazole, ofloxacin and amoxicillin. In our study, the highest susceptibility frequency was observed for ciprofloxacin, imipenem, meropenem, and ofloxacin with susceptibility frequency value of $100 \%$ each. This was closely followed by gentamicin and cefepime with susceptibility frequency value of $85.7 \%$ and $71.4 \%$ respectively (Table 2 ). The results of the one sample t-test conducted showed that there was no statistically significant difference in the mean percentage resistance of the $E$. coli isolates $(P=0.088$ (at $P<0.05)$. One sample t-test showed that there was a statistically significant difference in the mean percentage susceptibilities of the $E$. coli isolates $(P=0.000(P<0.05)$. Results of the independent samples t-test conducted to compare the percentage resistances and percentage susceptibilities of the $E$. coli isolates to different classes of antibiotics showed that there was a statistically significant difference in the mean percentage resistance and mean percentage susceptibility $(P=0.002(P<0.05)$. The result of our work shows that ciprofloxacin, gentamicin, meropenem, imipenem and ofloxacin are still active against bacterial infections caused by Escherichia coli in Abakaliki, Ebonyi state. Interestingly, our study also showed that ceftazidime, a third generation cephalosporin, is no longer effective in treating bacterial infections caused by Escherichia coli as $6(85.7 \%)$ out of the seven isolates obtained in this study were resistant to this particular antibiotic. Two (28.6\%) out of the seven (7) Escherichia coli isolates exhibited multi-drug resistance traits as 
they were resistant to at least two different classes of antibiotics

(Table 3).

Table 3 Antibiotic resistance patterns of the Escherichia coli isolates.

\begin{tabular}{|c|c|c|}
\hline $\mathbf{S} / \mathbf{N}$ & Isolate Code & Resistance Patterns \\
\hline 1. & E 7 & CAZR \\
\hline 2. & E 8 & FEPR CNR ATMR CAZR \\
\hline 3. & E 9 & ATMR \\
\hline 4. & E 10 & CAZR \\
\hline 5. & E 11 & CAZR \\
\hline 6. & E 12 & ATMR CAZR \\
\hline 7. & E 13 & CAZR \\
\hline \multicolumn{3}{|c|}{ Key: $\mathrm{R}=$ Resistant, $\mathrm{FEP}=$ Cefepime, $\mathrm{CN}=$ Gentamincin, $\mathrm{ATM}=$ Aztreonam, CAZ=Ceftazidime } \\
\hline
\end{tabular}

The average multiple antibiotic resistance index (MAR1) value of the Escherichia coli isolates was 0.335 and this signifies their high antibiotic resistance frequency values to commonly used antibiotic for treating bacterial infections (Table 4).

Table 4 Multiple Antibiotic Resistance Index (MARI) of Escherichia coli isolates.

\begin{tabular}{|c|c|c|c|c|c|c|c|c|c|c|c|}
\hline Isolates & E 14 & E 16 & E 18 & E 19 & E 20 & E 37 & E 38 & E 17 & E 46 & Total & Average \\
\hline MARI value & 0.143 & 0.57 & 0.63 & 0.143 & 0.143 & 0.143 & 0.143 & 0.43 & 0.143 & 2.345 & 0.335 \\
\hline
\end{tabular}

The multiple antibiotic resistance indices (MARI) of the $E$. coli isolates ranged from 0.143 to 0.335

The presence of microorganisms on paper currencies suggests that it can be a favourable environment for their growth. Presence of Escherichia coli on paper currencies could possibly suggest faecal contamination. It is a common practice among traders (butchers/meat sellers inclusive) to keep paper currencies on tables or squeeze them in their pockets or apron pockets. These unhygienic practices predisposes these traders to Escherichia coli infections especially Escherichia coli foodpoisoning. Consequently, proper handling of banknotes is of public health importance considering the fact that some communicable disease can spread by means of fomites including money.

\section{Conclusion}

This report has shown that naira notes collected from butchers in Abakaliki, Ebonyi State is contaminated with Escherichia coli. This may be as a result of faecal contamination through the faeces of the animals. This study also revealed that the $E$. coli isolates recovered were susceptible to most of the antibiotics used for this study, possibly due to lack of abuse of such antibiotics within the study area. This research work showed that few of the Escherichia coli isolates were multi-drug resistant. Our study has shown that ceftazidime is no longer effective in treating bacterial infections caused by $E$. coli as virtually all the $E$. coli isolates were resistant to this antibiotic, thus indicating a possible abuse of ceftazidime in our study area. The result of this study also revealed that ciprofloxacin, gentamicin, meropenem, imipenem and ofloxacin are still effective in treating bacterial infections caused by Escherichia coli. Escherichia coli contamination of paper currencies could pose a serious public health problem. Thus, proper sanitary handling of paper currencies and education of the populace on the negative effect of unhygienic handling of currencies should be done in possible cases to reduce community acquired infection in our society.

\section{Recommendation}

Currency is handled by all categories of people and may be contaminated during coughing, sneezing, touching with hands and placement on dirty surfaces. Many people tongue-wet their finger when counting money thereby contaminating their fingers as well as currency notes. So, it is obvious that anything that gets on hands may be transferred to money vice versa. Owing to the role of $E$. coli in infectious disease, it is therefore of public health importance to educate the populace on the effect of improper handling of paper currencies, especially the nursing mothers in our study area with the habit of allowing their children to play with paper currencies. These children, most times, end up putting these paper currencies in their mouths, thus predisposing them to bacterial infections. Further studies on the public health implication of bacterial contamination of paper currencies is therefore recommended to unveil more mysteries associated with paper currency contamination. 


\section{Conflict of Interest Statement}

The authors declare that there are no conflicts of interest

\section{References}

1. Kuria JK, Wahome RG, Jobalamin M, Kariuki SM (2009) Profile of bacteria and fungi on money coins. East Africa Medical Journal 86: 151-155.

2. Lamichhane J, Adhikary S, Guatam P, Maharjan R (2009) Risk of Handling Paper Currency in Circulation Chances of Potential Bacterial Transmittance. Nepal Journal of Science and Technol 10: 161-166.

3. Ahmed S, Parveen S, Nasreen T, Feroza B (2010) Evaluation of the Microbial Contamination of Bangladesh Paper Currency Notes (Taka) in Circulation. Advances in Biological Research 4: 266-271.

4. Angelakis E, Azhar El, Bibi F, Yasir M, Al-Ghamdi AK, et al. (2014) Paper Money and Coins as Potential Vectors of Transmissible Disease. Future Microbiology 9: 249-261.

5. Feglo P, Nkansah M (2010) Bacterial load on Ghanaian currency notes.African. J Microbiol Res, 4: 2375-2380.

6. Kaur T, Nafissi N, Wasfi O, Sheldon K, Wettig S, et al. (2012) Immunocompatibility of bacteriophages as nanomedicines.Journal of Nanotechnology, 12:181-196.

7. Gabriel EM, Coffey A, Mahony JMO (2013) Investigation into the prevalence, persistence and antibiotic resistance profiles of staphylococci isolated from euro currency. Journal of Applied Microbiology 115: 565-571.

8. Gedik H, Voss TA, Voss A (2013) Money and transmission of bacteria. Antimicrobial Resources Infectious Control 2: 22.
9. Gedik H, Yahyaoglu M, Yörük G, Fincaci M (2010) ExtendedSpectrum Beta- Lactamase production Rates of Klebsiella spp and Escherichia coli strains isolated from infections and fecal samples of healthy people. Infectious Diseases in Clinical Practice 18: 104-106.

10. Tolba O, Loughrey A, Goldsmith CE, Millar BC, Rooney PJ, et al. (2007) Survival of epidemic strains of nosocomial-and community acquired methicillin-resistant Staphylococcus aureus on coins. American Journal of Infectious Control 35: 342-346.

11. Cheesbrough M (2004) District Laboratory Practice in Tropical Countries, Part Two, 2ndEdition. Cambridge University Press, UK.

12. Clinical and Laboratory Standards Institute (2007) Performance Standards for antimicrobial Susceptibility testing. In Seventeenth edition Document M100-S17.Clinical and Laboratory Standards Institute, Wayne, Pennsylvania, USA.

13. Christopher AF, Hora S, Ali Z (2013) Investigation of plasmid profile antibiotic susceptibility pattern multiple antibiotic resistance index calculation of Escherichia coli isolates obtained from different human clinical specimens at tertiary care hospital in Bareilly-India. ATMPH 6: 285-289.

14. Subramani $P$, Shanmugam $N$, Sivaraman $U$, Kumar $S$, Selvaraj $S$ (2012) Antibiotic resistance pattern of biofilm-forming uropathogens isolated from catheterised patients in Pondicherry, India. Australas Med J 5: 344-348.

15. Ayandele AA, Adeniyi SA (2011)Prevalence and Antimicrobial resistance pattern of microorganism isolated from Naira notes in Ogbomosho North, Nigeria. Journal of Research in Biology 8: 597-593. 